INTERNATIONAL DESIGN CONFERENCE - DESIGN 2018

https://doi.org/10.21278/idc.2018.0231

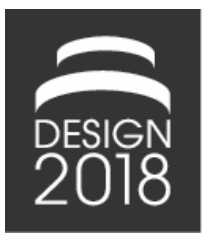

\title{
CONTINUOUS INTEGRATION OF MODEL VALIDATION INTO PRODUCT DEVELOPMENT
}

\author{
C. Forsteneichner, K. Paetzold and M. Metschkoll
}

\begin{abstract}
The validation of product properties is a necessary part of the product development process. Consequently, methods and models used therefor have to be validated itself in order to produce reliable results. This paper describes and exemplarily implements a process model that integrates model validation into product development. The CPM/PDD approach according to Weber (2005) provides the basic process model and the modeling procedure is based on VDI 2006 (2004) and ASME V\&V 10 (2006). The focus of the introduced process model is on continuous integration, consistency of data and knowledge storage.
\end{abstract}

Keywords: process modelling, design models, product development, verification and validation, simulation data management

\section{Introduction}

During product development, the final validation of product properties according to their requirements is of particular importance. To successfully pass through the associated milestone, varied abstraction levels have to be fulfilled using different validation methods. Such abstraction levels for example reach from the material to the component level up to the validation of assemblies and finally the whole product. In the product development process experimental as well as computer aided methods (CAx-tools) or hybrids of both are used. Therefore, a variety of modeling techniques have been developed. The associated complexity is usually increased by the variety of software systems and miscellaneous approaches of different departments.

The resulting interfaces between software systems and different users are a threat to efficiency of validation processes as well as consistency and traceability of data. They can result e.g. in communication and data loss issues, if the data transfer processes is not clearly defined. Such issues are crucial to the model validation procedure, which is an important precondition for the product properties validation, because the quality of results is ensured by model validation. Hence, model validation with inconsistent data can cause severe consequences on the validation of product properties. In this article a process model is introduced which focuses on data consistency and continuous embedding of model validation procedures into product development. The topic is illustrated by means of an industrial example from a motorcycle fuel tank development.

\section{Definition of verification and validation $(V \& V)$}

There are several definitions available for the terms verification and validation. Engel (2010) presents an overview of the most popular definitions and also discusses them. Following generic definitions are used in this paper. 


\subsection{Verification}

Verification is the "confirmation, through the provision of objective evidence, that specified requirements have been fulfilled." (ISO 9000, 2015).

"Verification is a set of activities that compares a system or system element against the required characteristics. This includes, but is not limited to, specified requirements, design description and the system itself" (ISO/IEC TS 24748-1, 2016).

Verification proves whether the system is created right (NASA, 2007, Balci, 2003).

\subsection{Validation}

Validation is the "confirmation, through the provision of objective evidence, that the requirements for a specific intended use or application have been fulfilled." (ISO 9000, 2015).

Validation is the set of activities that ensure and provide confidence that "[a] system is able to accomplish its intended use, goals and objectives (i.e. meet stakeholder requirements) in the intended operational environment." (ISO/IEC TS 24748-1, 2016).

Validation proves whether the right system was created (NASA, 2007, Balci, 2003).

\subsection{The meaning of the word system}

It is important to know in which context the verification and validation takes place. In other words, what is meant by the system? E.g. the word system can be replaced by the words product, service, enterprise or model (SEBoK authors, 2017).

Therefore, the objective of the process must be clear. For example, is the objective to develop a whole product or a component of a product? Furthermore, the objective could be to develop a model which represents the behavior of a system regarding the specific requirements to be investigated. The latter is the main context of verification and validation used in this paper. For clarification they are called model verification and model validation, if it is not obvious.

\section{Basic principles of process modeling}

\subsection{CPM/PDD approach according to Weber (2005)}

The approach is based on the differentiation between product characteristics $\left(\mathbf{C}_{\mathbf{i}}\right)$ and product properties $\left(\mathbf{P}_{\mathbf{j}}\right)$. Characteristics describe the product based on its shape, structure and materials. These can be directly influenced by the engineers. Unlike characteristics, product properties are indirectly determined by modifying characteristics. Properties describe the behavior of the product (e.g. durability, weight, strength, stiffness, regulatory compliance, etc.). The approach is divided into Characteristics Properties Modeling (CPM) and Property Driven Development (PDD). CPM describes product modeling by characteristics and properties. PDD is the process model based on CPM (see Figure 1) (Weber, 2005).

Table 1. CPM/PDD approach acronyms

\begin{tabular}{|c|c|}
\hline$C_{i}$ & Characteristics \\
\hline$D_{X}$ & Dependencies between characteristics \\
\hline$E C_{j}$ & External conditions \\
\hline $\mathrm{MC}_{\mathrm{j}}$ & Modelling conditions \\
\hline $\mathrm{P}_{\mathrm{j}}$ & Properties \\
\hline $\mathrm{PR}_{\mathrm{j}}$ & Required properties \\
\hline $\mathrm{R}_{\mathrm{j}}$ & Relations between characteristics and properties \\
\hline
\end{tabular}




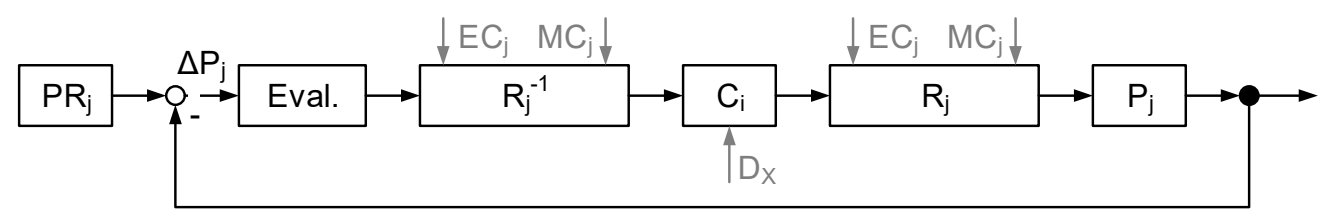

Figure 1. Abstract representation of product development as a control circuit (Weber, 2007)

\subsection{Procedure for model verification and validation extended by sensitivity analysis and optimizations}

VDI 2206 (2004) defines a procedure for modeling as shown in Figure 2.

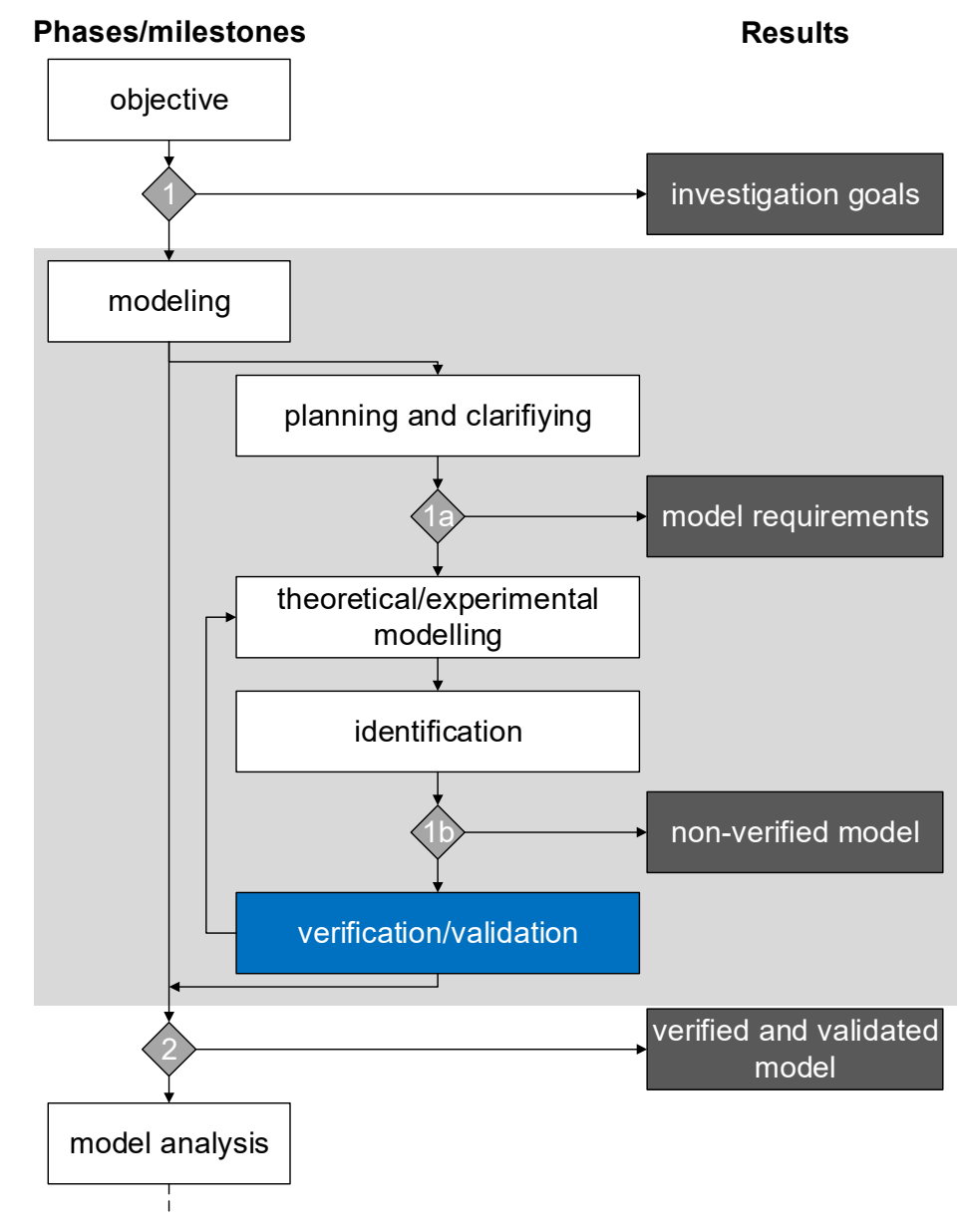

Figure 2. Procedure for modeling according to VDI 2206 (2004)

Therefore the procedure is integrated between the objective and the model analysis phase. It includes the procedure for model verification and validation, which is placed after the identification phase. In Forsteneichner et al. (2015), the process flow of model verification and validation is described in more detail and extended by sensitivity analysis and optimizations (see Figure 3). That extension has the following advantages:

- Support for the detection of model parameters that have a large impact on the result

- Improvement of the model quality

- Increasing efficiency and support for decision-making activities 
Instead of the procedure described in VDI 2206 (2004) it can also be integrated in the validation section of the ASME V\&V 10 (2006). After the model is verified and validated, the procedure is completed and the model is ready to be used in further model analysis and/or synthesis steps.

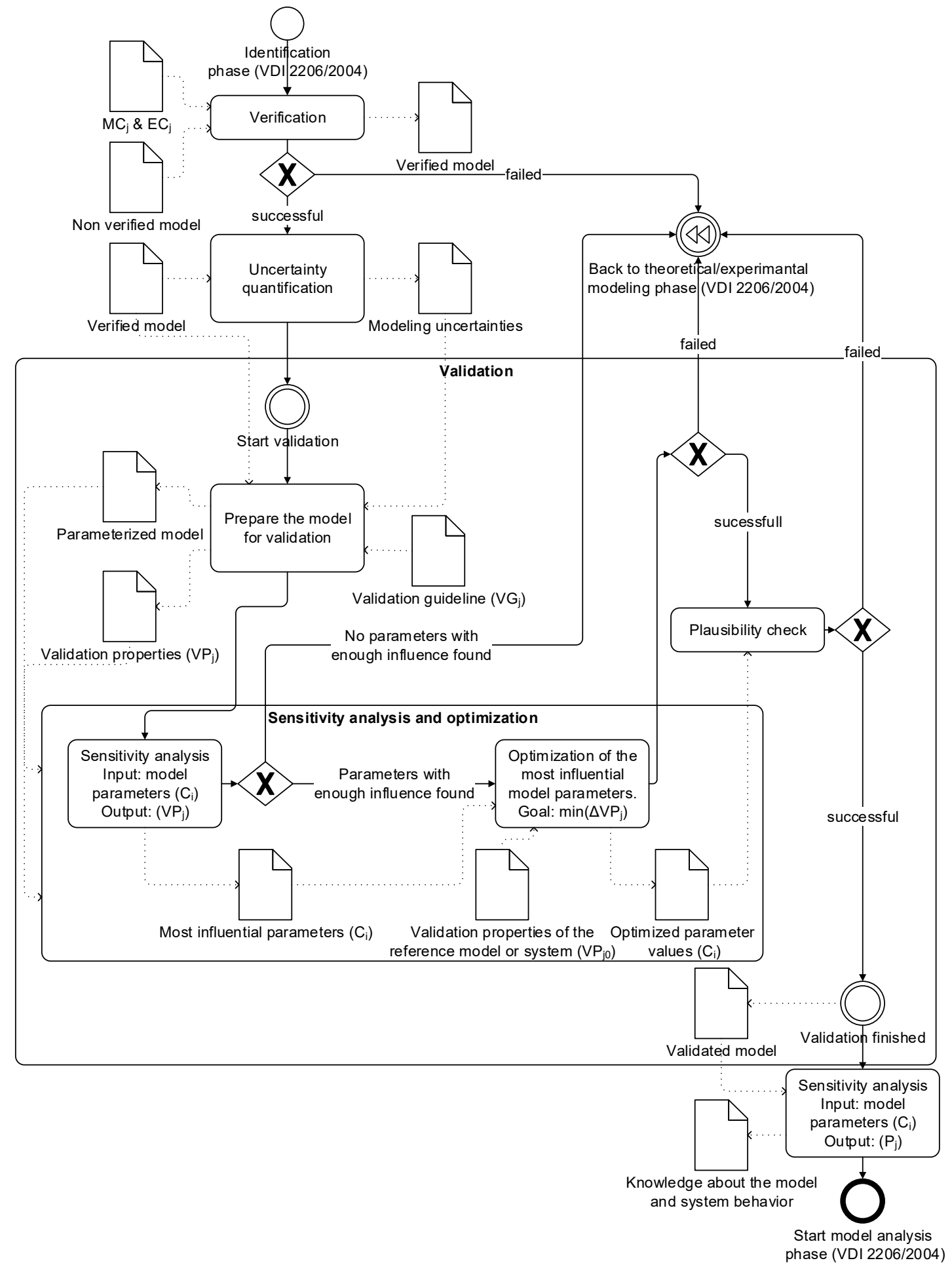

Figure 3. Procedure for model verification and validation

(Forsteneichner et al., 2015) 


\section{Continuous integration of the model validation procedure into the product development process}

\subsection{Process model for the continuous integration of the model validation into product development}

The CPM/PDD approach according to Weber (see Section 3.1) provides the basis for the process description, as it describes not only product information, but also process data. These data are important because they allow the connection between various CAx-tools and database systems (Vajna et al., 2009). The CPM/PDD approach is extended in Forsteneichner et al. (2016) by a control procedure which integrates the validation into the ongoing process of product development (see Figure 4). Validation executed at this point is especially efficient as the analytic models of the predecessor are only updated according to the product characteristics and external conditions such as boundary conditions. Then this model can be validated with the model of the current analysis step and there is no need to perform an additional one only for validation purpose. As a consequence, additional expenses for validation decreases. In addition, the control procedure will only be initiated if the degree of maturity of the current analysis step $\left(\mathbf{M}\left(\mathbf{R}_{\mathbf{j} \mathbf{A}}\right)\right)$ becomes significantly higher than that of the predecessor $\left(\mathbf{M}\left(\mathbf{R}_{\mathbf{j A}}\right)\right)$. A simple determination of the degree of maturity is not possible, but it can be estimated by experts for the concerning analysis steps. At best, there are existing methods for uncertainty quantification which can be used to quantify the degree of maturity and so support the decision-making process.

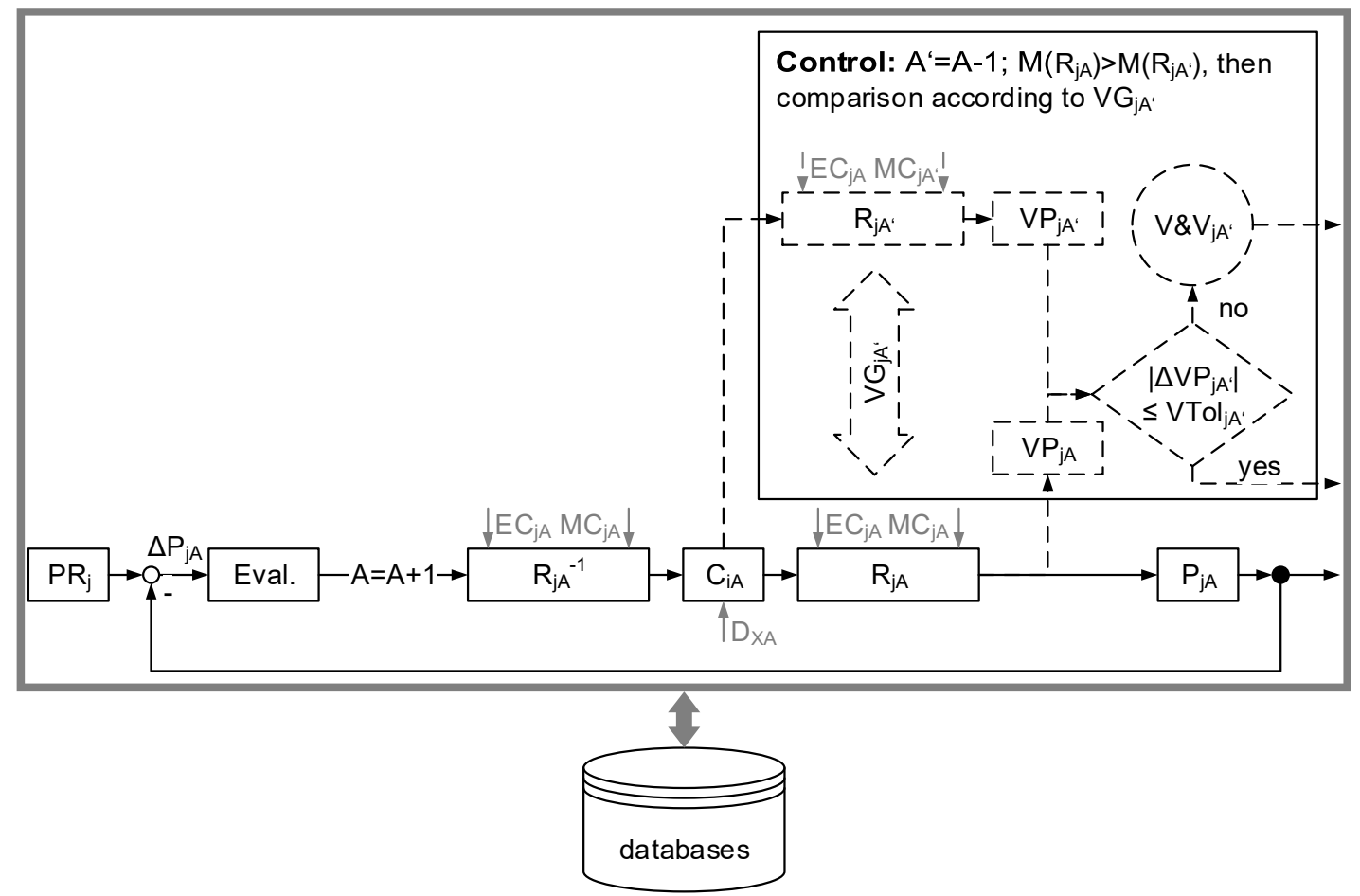

Figure 4. PDD extended by a control-procedure and information transfer

The whole procedure of verification and validation $\left(\mathbf{V} \& \mathbf{V}_{\mathrm{jA}}\right)$ (see Section 3.2) will only be started, if the deviations of the validation properties are not within the tolerance ranges, which are defined in the validation guideline $\left(\mathbf{V G}_{\mathbf{j A}}\right)$. Although the results of this procedure are relevant for the product development process, the procedure itself stays decoupled due to the immense effort a V\&V-procedure often requires. The outcome of this procedure is the knowledge why the validation is failing during the control procedure. According to this information the concerning data in the following categories are updated: $\mathbf{M C}_{\mathbf{j A}}, \mathbf{M C}_{\mathbf{j A}}, \mathbf{E C}_{\mathbf{j A}}, \mathbf{R}_{\mathbf{j A}}, \mathbf{R}_{\mathbf{j A}^{\prime}}, \mathbf{V G}_{\mathrm{jA}^{\prime}}$. Table 2 describes the data categories which are saved as attributes of data records on appropriate databases. For data consistency at least the name of the 
development process, the designation of the current cycle/phase and the categories of data to all records must be assigned as attributes in every database. This consistency is important because usually the databases in the IT landscape of companies are not directly linked. The following section demonstrates the introduced control procedure through an example and shows how standardization and automation can be implemented with the purpose of improving efficiency.

Table 2. Categories of data

\begin{tabular}{|c|c|}
\hline $\mathbf{A}$ & Number of cycles/phases passed through \\
\hline $\mathrm{C}_{\mathrm{iA}}$ & Characteristics \\
\hline $\mathbf{D}_{\mathrm{iA}}$ & Dependencies between characteristics \\
\hline $\mathbf{E C}_{\mathbf{j A}}$ & External conditions \\
\hline $\mathbf{P}_{\mathbf{j A}}$ & Properties (results of the analysis step) \\
\hline $\mathbf{P R}_{\mathbf{j}}$ & Required properties \\
\hline $\mathbf{R}_{\mathbf{j A}}$ & Methods and models of the analysis step \\
\hline $\mathbf{R}_{\mathrm{jA}}{ }^{-1}$ & Methods and models of the synthesis step \\
\hline $\mathbf{M C}_{\mathbf{j A}}, \mathbf{M C}_{\mathbf{j A}}$ & Modeling conditions of the current and previous analysis step \\
\hline $\mathbf{M}\left(\mathbf{R}_{\mathbf{j A}}\right), \mathbf{M}\left(\mathbf{R}_{\mathbf{j A}} \mathbf{A}^{\prime}\right)$ & Degree of maturity of the current and previous analysis step \\
\hline $\mathbf{V G}_{\mathbf{j A}} \mathbf{A}^{\prime}$ & Validation guidelines \\
\hline $\mathbf{V P}_{\mathbf{j A}}, \mathbf{V P}_{\mathbf{j A}}$ & Validation properties of the current and previous analysis step \\
\hline VTol $_{\mathbf{j A}}$ & Tolerance range of the validation deviation \\
\hline$\Delta \mathbf{P}_{\mathbf{j A}}$ & Deviation between the required properties and the current properties \\
\hline$\Delta \mathbf{V P} \mathbf{P}_{\mathbf{j A}}$ & Deviation between the validation of the current and previous analysis step \\
\hline
\end{tabular}

\subsection{Implementation example of the process model for a load case from motorcycle fuel tank development}

For better understanding, only one product property must be fulfilled in the following example. The required property shall be a resisted impact of a pendulum according to SAE guideline J1231 Nov. 1999. To show consistence of data despite different database systems, a development phase $(\mathbf{A})$ gets chosen, in which the fuel tank is inspected on the test rig $\left(\mathbf{R}_{\mathbf{j A}}\right)$ (see Figure 5, right). In the prior phase $\left(\mathbf{A}^{\prime}\right)$, detailed FE-simulations $\left(\boldsymbol{R}_{\boldsymbol{j} \boldsymbol{A}^{\prime}}\right)$ have already been performed (see Figure 5, left). These two phases have a considerable difference between the degrees of maturity of the two analysis steps $\left(\mathbf{M}\left(\mathbf{R}_{\mathbf{j A}}\right) \gg\right.$ $\mathbf{M}\left(\mathbf{R}_{\mathbf{j A}} \mathbf{A}^{\prime}\right)$ ), because of significant uncertainties due to the transition from a virtual to the physical method. Therefore, the control procedure can be illustrated.
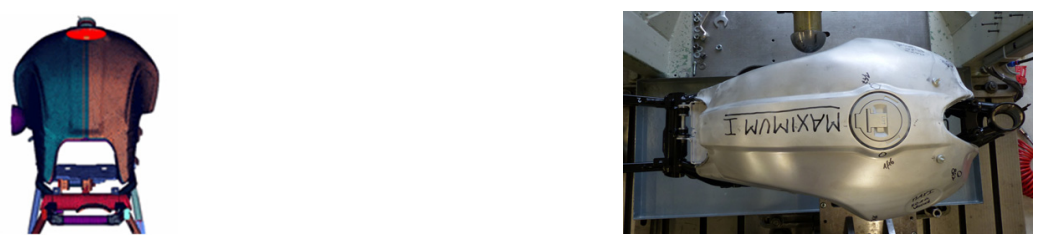

Figure 5. FE-simulation (left); physical test (right)

The current product characteristics $\left(\mathbf{C}_{\mathbf{i A}}\right)$ and their dependencies $\left(\mathbf{D}_{\mathbf{i A}}\right)$ provide the starting point. The model of the prior phase has to be updated accordingly. This includes e.g. parameter-based CAD (computer aided design) geometry of the fuel tank and its connecting components as well as utilized materials. The following two figures illustrate the control procedure from the point of view of the simulation discipline for this example. Many steps of the procedure are automated (see 目 in Figure 6 and 7) within the simulation database system with the purpose of increasing efficiency. It also demonstrates the amount of data and the variety of databases which can accrue during the control procedure. 


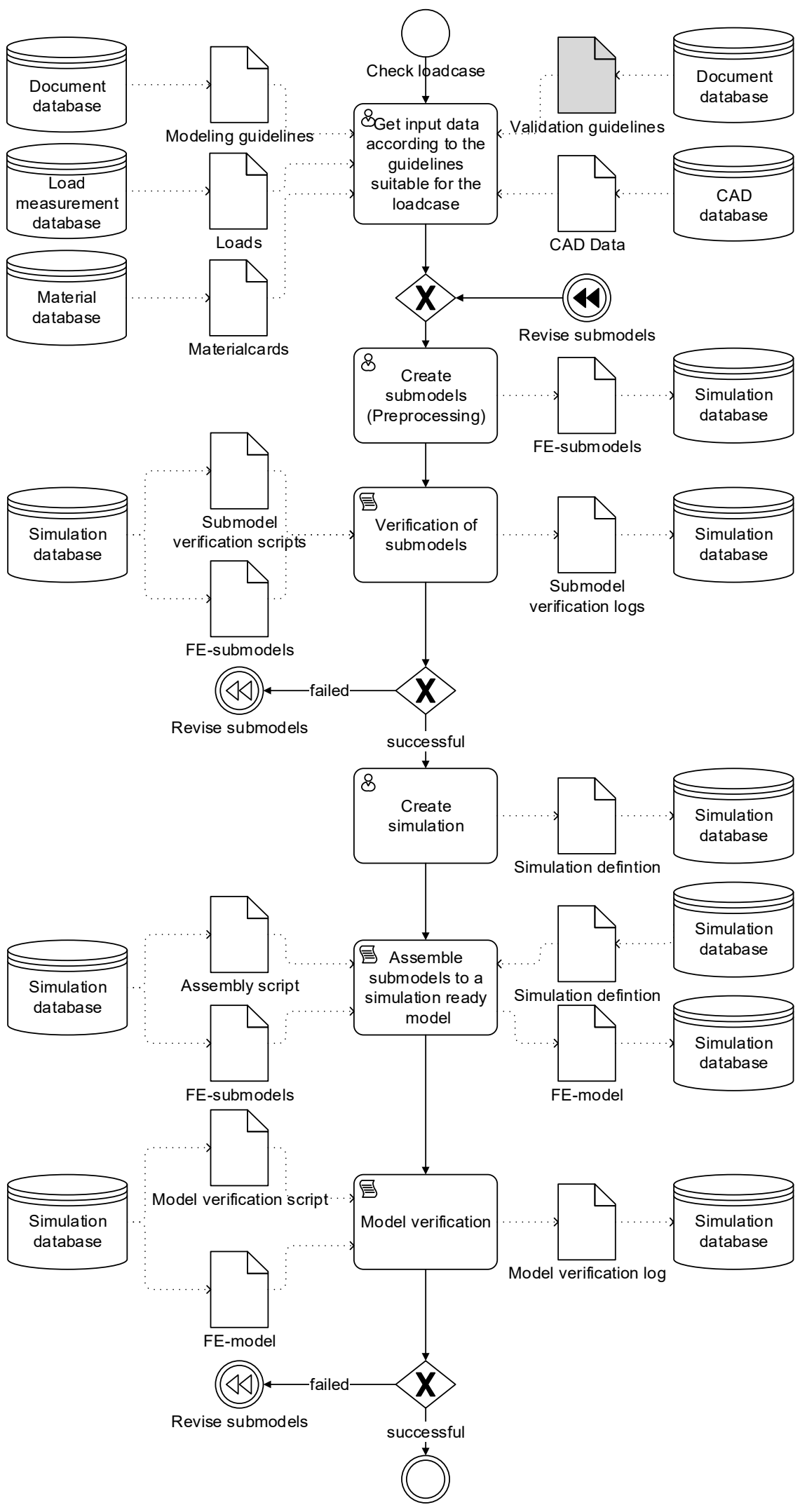

Figure 6. Check procedure within the simulation database system (part 1) 


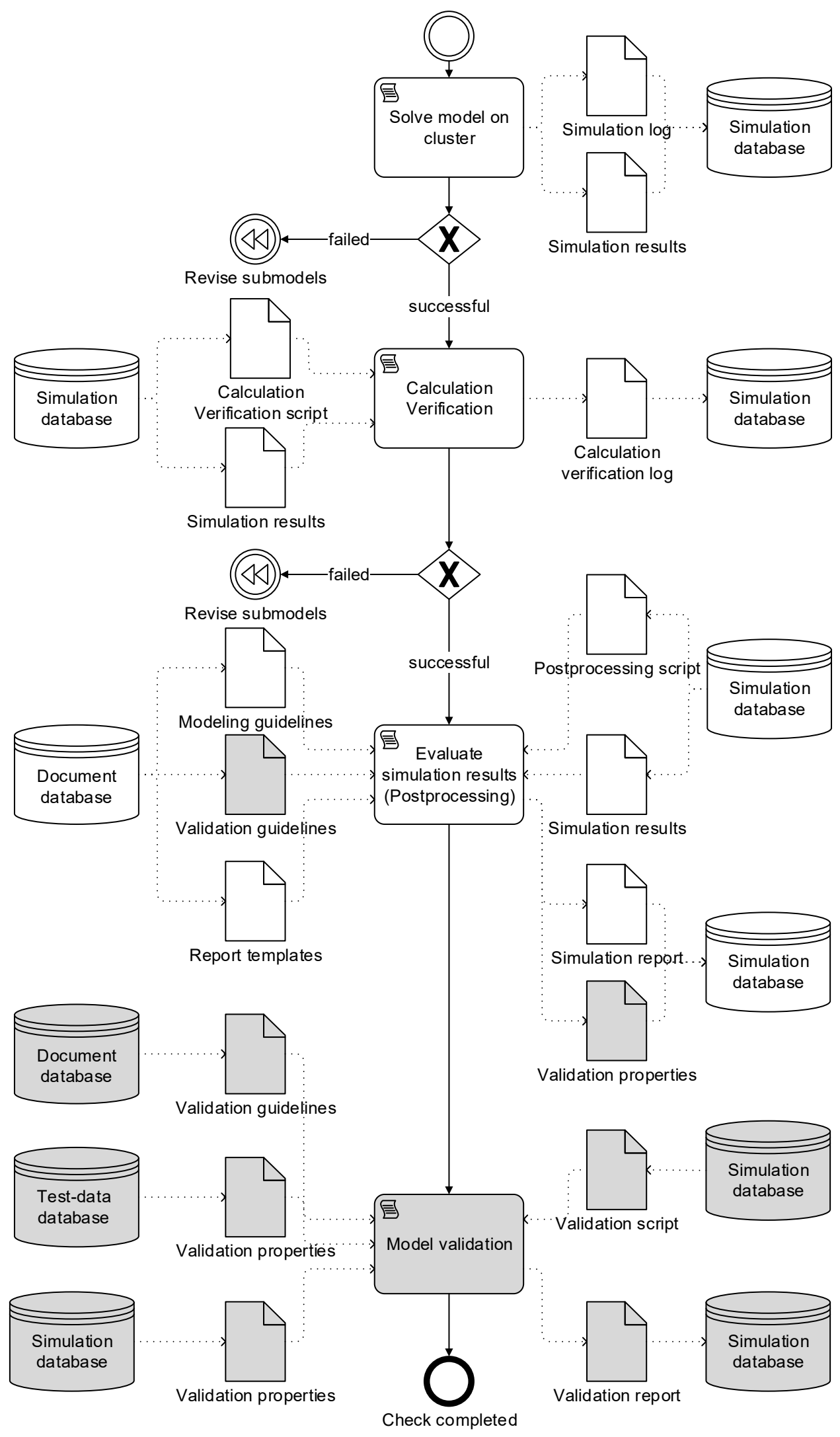

Figure 7. Check procedure within the simulation database system (part 2) 
After getting input data, model creation is initiated. Instead of creating the whole model at once, it is split into submodels. This has following advantages:

- Parallel creation of submodels e.g. by different persons

- Submodels can be reused from/in other simulations

These advantages can only be achieved by a greater effort in planning and organization of their creation. This effort can be reduced by standardization (see Section 4.2.1). Another benefit results from the verification of submodels. In this step, the submodels are checked if they are built accordingly to their modeling guideline. Thus, formal errors can be identified before the whole model exists. This makes the error tracing faster. Some verifications can only be performed on the assembled model, e.g. if everything is connected properly. After model solving the last verification step takes place. The calculation verification inspects the simulation results for possible errors - e.g., if there are jumps in energy outputs where they are not plausible, or mass scaling of a model region exceeds a threshold value.

If everything is okay, the simulation results have to be evaluated in the postprocessing step. In a standard simulation process this is the last step, but the objective of the check procedure is the model validation. The gray-filled icons illustrate the additional effort required by model validation. There is also further work to be done in the previous steps. This work can be combined with their standard procedures (see Section 4.2.1). If these steps are automated, they can have extra start parameters to extend their functionalities in terms of model validation.

\subsubsection{Standards}

The following guidelines and standards support the user in modeling, reporting and also in the validation process. With their help the above-mentioned interface issues and communication problems are reduced. Modeling guidelines / testing guidelines $\left(\mathrm{MC}_{\mathrm{jA}}, \mathrm{ECI}_{\mathrm{jA}}\right)$ serve as a handbook for modeling, running and evaluating simulations. Their equivalent for physical tests are the so called testing guidelines, which describe test setup, test procedure and evaluation. Furthermore, both standards explain the application range of the methods and their limits of use.

Report templates $\left(\mathrm{MC}_{\mathrm{jA}^{\prime}}, \mathrm{MC}_{\mathrm{jA}}\right)$ are provided to illustrate the results of simulations or physical tests. Validation guidelines $\left(\mathrm{VG}_{\mathrm{jA}^{\prime}}\right)$ point out the standards that are necessary to prepare and perform analysis steps. In the current example these are the modeling guidelines, testing guidelines and report templates for the fuel tank. Additionally, they regulate the communication and data exchange between the involved disciplines like design, simulation and physical testing. They also include the following preconditions for successful validation formulated as questions and provide assistance in answering them:

- Get input data step: Is the FE-model based on the current product characteristics (e. g. CAD geometry and material cards) and external boundary conditions - e. g. load data?

- Model verification step: Is the FE-model created correspondingly to their guideline and are the additional efforts implemented correctly to get the validation properties?

- Calculation verification step: Are the results of simulation and test plausible?

- Evaluation step: Are the evaluations performed accordingly to modeling guidelines, testing guidelines and report templates?

- Uncertainty quantification: How big are the uncertainties of the results?

The definition of validation properties $\left(\mathbf{V P}_{\mathbf{j A}}, \mathbf{V P}_{\mathbf{j A}} \mathbf{A}^{\prime}\right)$ is the core of the guidelines. Of similar importance are the detailed specifications of the required additional effort, determination of deviations and their tolerance range. The validation property in the given example is the deformation of the fuel tank caused by the impact of a pendulum. Since the simulation results already contain the deformation data, this does not cause any additional effort (see Figure 8). The surface of the tank is scanned before and after the pendulum impact, so that the experimental results include deformation data as well (see Figure 9). 


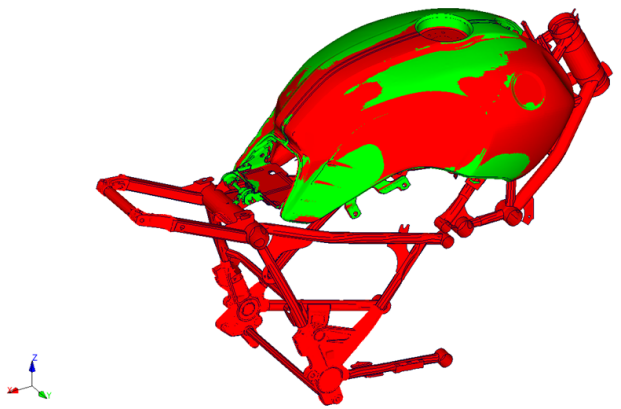

Figure 8. FE-model (red) and scan data before impact (green)

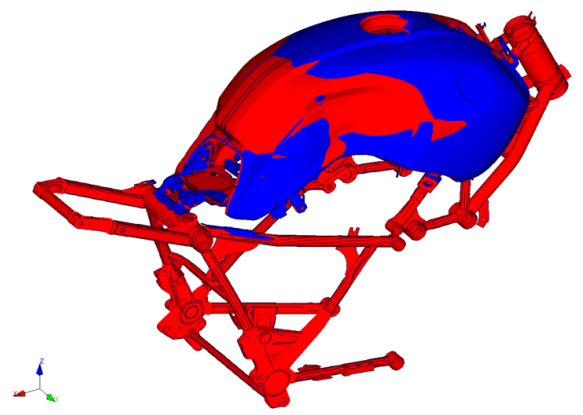

Figure 9. FE-simulation (red) and scan data after impact (blue)

Alignment of the scan data, which are collected prior to the impact, to the undeformed FE-model is derived by using the connection points at the frame. The resulting transformation matrix gets saved and applied on the scan data collected after the impact. As soon as the scan data is aligned, the deviations of the deformation can be calculated (see Equation 1). Therefore, the Cartesian distance between FE-model and scan data prior to the impact is determined for each node. The same needs to be done with the distance between the FE-model and the scan data collected after the impact. Now the differences of both distances have to be computed. The arithmetic mean of those differences match the average deviation of the compared deformations.

$$
\bar{D}_{\text {korr }}=\frac{\sum_{i=1}^{k}\left|\left(\begin{array}{l}
x_{n_{i}} \\
y_{n_{i}} \\
z_{n_{i}}
\end{array}\right)-\left(\begin{array}{l}
x_{v_{i}} \\
y_{v_{i}} \\
z_{v_{i}}
\end{array}\right)\right|}{k}=\left|\Delta V P_{j A^{\prime}}\right|
$$

With:

$$
\begin{aligned}
& \left(\begin{array}{l}
x_{v_{i}} \\
y_{v_{i}} \\
z_{v_{i}}
\end{array}\right) \text { : Cartesian distance between FE-model and scan data before the impact } \\
& \left(\begin{array}{l}
x_{n_{i}} \\
y_{n_{i}} \\
z_{n_{i}}
\end{array}\right) \text { : Cartesian distance between FE-model and scan data after the impact }
\end{aligned}
$$

$\mathrm{k}$ : Number of nodes in the evaluation area (see Figure 10)

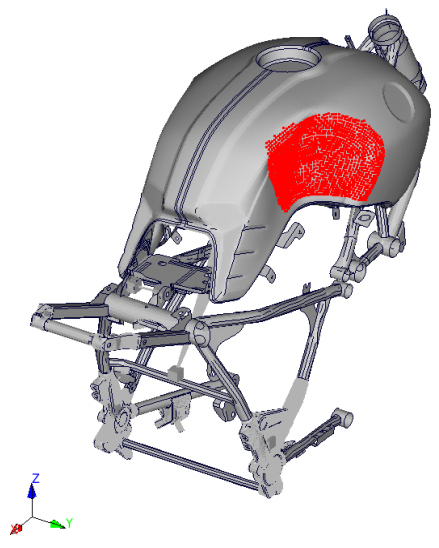

Figure 10. Nodes (red) in the evaluation area

Eventually, the average deviation $\left(\Delta \mathbf{V} \mathbf{P}_{\mathbf{j} \mathbf{A}^{\prime}}\right)$ is compared to the defined tolerance range $(\mathbf{V T o l} \mathbf{j A})$. By doing so, the decision is made whether the deformation of the FE-model sufficiently matches the deformation of the actual experiment. If this is the case, the validation is completed successfully. 


\subsubsection{Automation potential}

The previous section shows the high amount of additional work that is associated with the validation procedure. Consequently, the whole process should be highly automated (see Figure. 6 and 7; 尽). The three verification steps reveal formal errors as soon as possible and thus ensure the quality of the simulation. Some steps still need to be performed by the user (see Figure. 6 and 7, 8). These can be further reduced. For example, the creation of submodels can be largely automated by the use of batchmeshing.

\subsubsection{Conservation of knowledge}

If the validation was not finished successfully, as shown in Section 3.1, the process of verification and validation $\left(\mathbf{V} \& \mathbf{V}_{\mathrm{jA}^{\prime}}\right)$ gets initiated once again (see Figure 3 ). The collected knowledge is used to update related standards accordingly. Corresponding examples are presented in Table 3.

Table 3. Collected knowledge and the resulting update in the related standard

\begin{tabular}{|l|l|l|}
\hline Knowledge & Standard & Update \\
\hline $\begin{array}{l}\text { Current validation properties are } \\
\text { insufficient for the validation procedure. }\end{array}$ & $\begin{array}{l}\text { Validation } \\
\text { guideline }\end{array}$ & $\begin{array}{l}\text { Current validation properties are replaced by } \\
\text { newly developed ones. }\end{array}$ \\
\hline $\begin{array}{l}\text { Discretization of fuel tank content (fluid) } \\
\text { with SPH (smoothed-particle } \\
\text { hydrodynamics) method. }\end{array}$ & $\begin{array}{l}\text { Modeling } \\
\text { guideline }\end{array}$ & Discretization of fuel tank content is updated. \\
\hline Wrong signal due to a defect sensor. & Testing guideline & $\begin{array}{l}\text { Sections for inspection of sensors and } \\
\text { plausibility controls of signals are included. }\end{array}$ \\
\hline
\end{tabular}

\subsubsection{Records of the control procedure}

Table 4 shows the records that accrued during the complete control procedure (see also Figures. 6 and 7) and assigns the corresponding categories and databases. All records have attributes as outlined in section 4.1. This allows a consistent compilation of all records across every database.

Table 4. Resulting records of the control procedure

\begin{tabular}{|c|c|c|}
\hline Records & Database & $\begin{array}{l}\text { Categories of } \\
\text { data }\end{array}$ \\
\hline Load data & Load measurement database & $\mathbf{E C}_{\mathbf{j A}}$ \\
\hline Material cards & Material database & $\mathrm{C}_{\mathrm{iA}}$ \\
\hline Modeling guidelines & Document database & $\mathbf{M C}_{\mathbf{j A}}, \mathbf{E C}_{\mathbf{j A}}$ \\
\hline Parameter based CAD data, materials & $\begin{array}{l}\text { CAD database within the PDM } \\
\text { (product data management) } \\
\text { system }\end{array}$ & $\mathbf{C}_{\mathrm{iA}}, \mathrm{D}_{\mathrm{iA}}$ \\
\hline Report templates & Document database & $\mathbf{M C}_{\mathbf{j A}}, \mathbf{M C}_{\mathbf{j A}}$ \\
\hline $\begin{array}{l}\text { Simulation data (FE-model, solver version, applied } \\
\text { modeling guidelines and report templates), results, } \\
\text { reports, validation property, validation deviation and its } \\
\text { tolerance range }\end{array}$ & Simulation database & $\begin{array}{l}\boldsymbol{R}_{j A^{\prime}}, V P_{j A^{\prime}} \\
\Delta \mathbf{V P}_{\mathrm{jA}^{\prime}}, \mathbf{V T o l}_{\mathrm{jA}}\end{array}$ \\
\hline $\begin{array}{l}\text { Test data (test rig, applied testing guidelines and report } \\
\text { templates), results, reports and validation property }\end{array}$ & Test data database & $\begin{array}{l}\mathbf{R}_{\mathbf{j A}}, P_{\mathbf{j A}}, \Delta \mathbf{P}_{\mathbf{j A}} \\
\mathbf{V P}_{\mathbf{j A}}\end{array}$ \\
\hline Testing guidelines & Document database & $\mathbf{M C}_{\mathbf{j A}}, \mathbf{E C}_{\mathbf{j A}}$ \\
\hline Validation guideline & Document database & $\mathbf{V G}_{\mathbf{j A}}$ \\
\hline
\end{tabular}




\section{Conclusion}

Based on the product driven development process (PDD) according to Weber a control procedure is introduced which integrates the model validation continuously into the development process to ensure their predictive quality. The integration at this point is efficient since the predecessor model gets only updated and the current model can be enriched so that its results can be used additionally for validation. The time consuming model verification and validation procedure, introduced in Section 3.2, gets only started, if the model validation, initiated by the check procedure, fails. Furthermore, this procedure is decoupled from the product development process, so that it has no negative influence on its progress.

The example gives a guidance on how the control procedure can be implemented and performed. It illustrates the importance of automation to reduce the amount of additional effort, how the knowledge can be stored by updating the standards and the consistent storage of the records in databases.

\section{References}

ASME V\&V 10 (2006), Guide for verification and validation in computational solid mechanics, American Society of Mechanical Engineers (ASME), New York.

Balci, O. (2003), "Verification, validation, and certification of modeling and simulation applications", Proceedings of the 2003 Winter Simulation Conference, 7-10 Dec. 2003, New Orleans, LA, USA. https://doi.org/10.1109/WSC.2003.1261418

Forsteneichner, C., Metschkoll M. and Paetzold K. (2015), "Methodische Vorgehensweise zur Verifikation und Validierung komplexer Systeme”, In: Krause, D., Paetzold, K., Wartzack, S. (Ed.), Design for X: Beiträge zum 26. DfX Symposium, 7.-8. October 2015, TuTech-Verlag, Hamburg, pp. 145-156.

Forsteneichner, C., Metschkoll M. and Paetzold K. (2016), "Modellierung eines durchgängigen Prozesses zur virtuellen Absicherung von Produkteigenschaften", Berechnung und Simulation: Anwendungen Entwicklungen - Trends: 3. NAFEMS DACH Regionalkonferenz: unabhängig - übergreifend - neutral, Bamberg, 25.-27 April 2015, NAFEMS GmbH, Bernau am Chiemsee, pp. 241-244.

ISO 9000 (2015), Quality management systems - fundamentals and vocabulary, 4th edition, ISO Copyright office, Geneva.

ISO/IEC TS 24748-1 (2016), Systems and software engineering -- Life cycle management -- Part 1: Guidelines for life cycle management ISO Copyright office, Geneva.

NASA (2007), Systems engineering handbook, NASA/SP, 2007-6105, Rev. 1, National Aeronautics and Space Administration, Washington, D.C., pp. 83-106

SEBoK authors. (2017), System Validation -- Guide to the Systems Engineering Body of Knowledge (SEBoK), version 1.8. [online]. Hoboken, NJ: The Trustees of the Stevens Institute of Technology (C2017. Available at: http://sebokwiki.org/w/index.php?title=System_Validation\&oldid=51704 (accessed 26.11.2017).

Vajna, S., Weber, C., Bley, H., Zeman, K. and He⿳亠丷enberger, P. (2009), "Methodische Grundlagen", In: CAx für Ingenieure, Springer Berlin Heidelberg, Berlin, Heidelberg, pp. 21-56. https://doi.org/10.1007/978-3-540$36039-12$

VDI 2206 (2004), Design Methodology for Mechatronic Systems, VDI-Verlag, Düsseldorf.

Weber, C. (2005), "CPM/PDD - An extended theoretical approach to modelling products and product development processes”, In: Bley, H., Jansen, H., Krause, F.-L., Shpitalni, M. (Ed.), 2nd German-Israeli Symposium on Advances in Methods and Systems for Development of Products and Processes, 07.-08 July 2005, Fraunhofer-IRB-Verlag, Stuttgart, pp. 159-179.

Weber, C. (2007), "Looking at "DFX" and "Product Maturity" from the Perspective of a New Approach to Modelling Product and Product Development Processes", In: Krause, F.-L. (Ed.), The Future of Product Development, 26.-28. March 2007, Springer Berlin Heidelberg, Berlin, Heidelberg, pp. 85-104. https://doi.org/10.1007/978-3-540-69820-3_11

Christian Forsteneichner, M.Eng.

BMW AG, BMW Motorcycle, R\&D Body, Special Vehicles

Hufelandstrasse 20, 80788 Munich, Germany

Email: Christian.Forsteneichner@bmw.de 